\title{
When Bad People Happen to Good Games
}

Josh Coates, Internet Archive

\author{
Being a jerk MAY NOT \\ BE AGAINST GAME RULES, \\ BUT DEVELOPERS SHOULD \\ DO MORE TO STOP IT.
} geek, I admit that I actually care enough to be bitter about it. Yep, that's right-this puts me in the "bigtime nerd" category.

But I think I have a lot of company, which sort of makes me feel better. In fact, at any given moment there are hundreds of thousands of people online playing games. Sure, some of them are playing very simple games like Yahoo! Checkers, and others are playing complicated realtime strategies like Blizzard's Starcraft-but no matter what game they are playing, they are playing with other people. This is the real attraction of online games. No matter how good games get at so-called artificial intelligence, humans will always make more interesting teammates or opponents. That's a good thing, but it's also a bad thing. And this is where the bitterness comes in.

All right, this is the armchair psychology part of my rant: Anonymity breeds meanness. It's really simple: If you don't know someone, and they don't know you-and there is like a zero percent chance that you will ever know each other-and they cut you off, make an insulting remark, or inconvenience you in any way, you're going to fly off the handle at them. That's just the way people are.

Back to online games. The fun (as in "wow, this sucks" kind of fun) thing about the anonymity of online game players is that they can get very creative in their sociopathic behavior. This creativity gets cultivated and transferred from one idiot to another, and voila-you've got a perfectly fun game that has become crippled by morons. What kind of behavior am I talking about? Here's a sample:

\section{SMACKTARDS (AKA GRIEFERS)}

This is the classic condition. Smacktards do the exact opposite of what they are supposed to be doing. Playing capture the flag? They will take their own team's flag and run it to the other side. First-person shooter game? They will shoot their own teammates. Realtime strategy? They will spend their time building senseless walls around their teammates' armies. If your goal in life were to ruin the game experience of as many people as possible, then you would be a perfect smacktard/griefer.

\section{OLD-FASHIONED CHEATING}

\section{CLAN/ADMIN ABUSE}

I've got a great idea! Why don't we form "membersonly" gaming clubs that

will filter out the idiots? That way we can actually have fun with serious game players. Duh! It turns out that a vast majority of bad behavior is perpetrated by players affiliated with these clans. Yep, I'm talking about an organized roving gang of immature cretins.

This bad behavior usually occurs when someone in the clan gets their feelings hurt. If they aren't playing quite as well as they usually do that day, and some nonclan member makes a friendly (read: offensive) suggestion, all heck will break loose-usually in the form of a vote-kick or team-killing of the offending person. (A vote-kick is when the group of online players votes on whether or not to boot a player from a server. A team-kill is when someone on your team decides to kill you.) Oftentimes, a clan will run its own game servers and invite the public to become cannon fodder. If the unwary public gets out of line (e.g., by playing better than a clan member or suggesting that the clan game server needs a CPU upgrade), then they get summarily booted off the server by the clan admin.

Some people just have to win. No matter what. So they cheat. Cheating is when players use some client-side software that gives them an unfair advantage over the other remote players. These kinds of cheats usually just intercept the server-to-client communication and make "adjustments" where necessary. These adjustments can make your aim perfect, make it so you can "see" people on the map that you couldn't normally see, make you move faster than you should be able to, etc. This kind of stuff is actually becoming less common because it is technically difficult to do, and game developers are starting to get a clue and building in preventatives for it.

Interestingly, the average age of an online game player is 29 , so we can't blame this idiotic behavior on immature teenagers. The blame must be placed on immature people. Even though ageism is alive and well in the real world, it Continued on page 91 
Continued from page 92

doesn't carry any weight in the online world. There are really great teenage players who are mature and make excellent competitors and teammates. There are also teenagers who are the complete morons that you'd expect them to be: four-letter-word-littered chatter, sexism, racism, and delusions of grandeur-all rolled up into one. Of course, many adults have these traits as well.

\section{GAME DEVELOPERS}

Wait a second-I'm bitter about game developers, too. You can't change human nature, but you sure as heck can engineer around it. The problem is that the game developers don't care about these issues. Very few games are engineered with implicit anti-idiot features. I'm not sure why. Could it be that game designers play the game in the sterile vacuum of the QA (quality assurance) lab with their administrative privileges ready to stamp out injustice?

Perhaps game developers don't realize they're enabling roving gangs of sociopaths who are effectively destroying the virtual world the developers have worked so hard to create. I'm guessing that if they played with the unwashed masses as a regular n00b (that's nerdish for newbie), they would soon feel the pain of irresponsible game engineering and likely think a little more about how to include implicit fairness mechanisms in their next design.

Hey, game developers, need a clue? Drop me an e-mail at jcoates@archive.org and I'll see if I can help out. Q

\section{LOVE IT, HATE IT? LET US KNOW}

feedback@acmqueue.com or www.acmqueue.com/forums

JOSH COATES is the director of engineering and operations at the Internet Archive, a nonprofit dedicated to preserving digital media. In 1999, he founded Scale8, which launched the largest Internet storage system in the world, spanning three continents. Prior to founding Scale8, Coates worked at Inktomi Corporation developing network caching software applications. In 2001 he was named one of Red Herring magazine's Top Ten Innovators, and in 2002 he received MIT Technology Review's Top 100 Innovators Award. Coates received a B.S. in computer science at the University of California, Berkeley, and was active in the Network of Workstations (NOW) Group and Millennium Project.

@2004 ACM 1542-7730/04/0200\$5.00 